\title{
Ocorrência e fatores de risco da criptosporidiose em felinos de companhia de idosos
}

\author{
Occurrence and risk factors for cryptosporidiosis in cats company for elderly
}

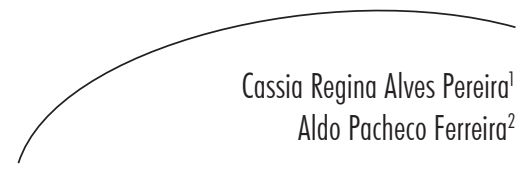

\section{Resumo}

Pesquisou-se a prevalência de criptosporidiose em gatos domésticos de companhia em idosos de ambos os sexos (acima de 60 anos de idade) proprietários dos mesmos, residentes no município de Teresópolis-RJ e que compareceram a um posto de vacinação do município no período da vacinação contra gripe de 2009 e 2010 . A prevalência de diarreia nos idosos foi $29,4 \%$ e nos felinos $24,5 \%$. Identificou-se presença de um ou mais oocistos em 16,7\% dos idosos e em 12,7\% nos felinos. A análise da razão de prevalência de diarreia evidenciou uma forte associação em idosos ( $\mathrm{RP}=4,37$, IC a $95 \%: 2,67$ - 7,16) e menor força de associação em felinos (RP = 2,16, IC a 95\%: 1,06 - 4,39). Pela análise de imunofluorescência confirmada pela PCR, houve semelhante força de associação em idosos ( $\mathrm{RP}=4,43$, IC a 95\%: 3,04 - 6,45), mas se observou aumento na força de associação para felinos (RP = 4,67, IC a 95\%: 3,9 - 6,81). Os achados obtidos com esta pesquisa são preocupantes, mas importantes para a saúde pública, por demonstrarem a relação zoonótica do Cryptosporidium spp. presente nas amostras fecais dos animais de companhia do grupo populacional de idosos estudados.

\section{Abstract}

The prevalence of cryptosporidiosis was analyzed in domestic cats and in their elderly owners (over 60 years of age) of both sexes, residents in the city of Teresópolis, and who were attended by a vaccination against influenza in 2009 and 2010 . The prevalence of diarrhea in the elderly was $29.4 \%$ and $24.5 \%$ in cats. It was identified the presence of one or more oocysts in fecal material in $16.7 \%$ of elderly, and $12.7 \%$ in cats. The prevalence of diarrhea showed strong association in elderly people ( $\mathrm{PR}=4.37,95 \% \mathrm{CI}$ : 2.67 to 7.16), and lower strength of association in cats (PR $=2.16,95 \% \mathrm{CI}: 1.06-4.39$ ). By immunofluorescence confirmed by PCR there was similar strength of association in elderly people ( $\mathrm{PR}=4.43,95 \% \mathrm{CI}$ : 3.04 to 6.45 ), but there was an increase in the strength of association for felines ( $\mathrm{PR}=4.67,95 \% \mathrm{CI}: 3.9$ to 6.81 ). The findings

\section{Palavras-chave:}

Cryptosporidium. Prevalência. Saúde do idoso. Animais de companhia. Teresópolis-RJ.
Key words: Cryptosporidium. Prevalence. Pets. Health of the elderly. Companion animals. Teresópolis-RJ.

1 Centro Universitário Plínio Leite. Niterói, RJ, Brasil.

2 Centro de Estudos da Saúde do Trabalhador e Ecologia Humana. Escola Nacional de Saúde Pública Sérgio Arouca. Rio de Janeiro, RJ, Brasil. 
from this research are disturbing, but important to public health, as they show the relationship of zoonotic Cryptosporidium spp. present in fecal samples of companion animals from the population elderly studied.

\section{INTRODUÇÃO}

A criptosporidiose é uma importante zoonose responsável por manifestações clínicas de diarreias e gastrenterites, associado à dor abdominal em seres humanos e causada por protozoários oportunistas do gênero Cryptosporidium. ${ }^{1}$ É transmitida entre indivíduos por meio de oocistos que já são eliminados na forma infectante, sendo as principais vias de transmissão o contato direto (pessoa a pessoa), oral/fecal ou indiretamente, pela ingestão de alimentos ou água contaminados (oocistos). ${ }^{2}$ Sua distribuição é cosmopolita, apresentando vários hospedeiros, em que o $C$. muris foi a primeira espécie descrita, em 1907 por Tyzzer, sendo seu desenvolvimento endógeno restrito às glândulas estomacais de roedores. O C. parvum, também descrito por Tyzzer (1912), ocorre principalmente no intestino delgado de vários mamíferos, incluindo o homem. ${ }^{3}$

O protozoário parasita Cryptosporidium emergiu como um importante contaminante da água, responsável por vários surtos de criptosporidiose, afetando, até meados de 2001, aproximadamente 427 mil pessoas em todo mundo.

Embora o C. parvum e o $C$. hominis sejam as espécies de ocorrência mais frequente nos humanos, com maior expressividade, o C. parvum tem sido associado às doenças gastrintestinais, ${ }^{3,4}$ apresentando-se como uma doença fatal em imunocomprometidos e que pode debilitar severamente indivíduos imunocompetentes. ${ }^{2}$ Oocistos de Cryptosporidium podem sobreviver por vários meses no ambiente aquático e são também resistentes à desinfecção por cloro, utilizada no tratamento convencional de água. ${ }^{5}$

OC.parvumtemsidoreconhecidomundialmente como um dos maiores contaminantes das águas de consumo. ${ }^{5}$ A descrição da contaminação dos recursos hídricos pela presença de oocistos, provavelmente de origem humana e animal, estão frequentemente associadas a surtos diarreicos e, consequentemente, a altas taxas de morbidade e mortalidade, atingindo preferencialmente imunocomprometidos e crianças, mas também imunocompetentes e animais. ${ }^{2,6}$ Embora de características endêmicas, a diarreia pode apresentar casos relacionados entre si (clínica, distribuição espaço-temporal, fonte de infecção) que são capazes de caracterizar um surto. Estudos desenvolvidos a partir dos anos 1980 estabeleceram que o Cryptosporidium não é espécie-específico, ${ }^{4}$ e que linhagens de uma espécie animal podem infectar um amplo espectro de outras espécies, indicando que os hospedeiros e reservatórios são múltiplos na natureza e que uma espécie animal pode contrair a infecção de outra. ${ }^{5,6}$

A ausência de uma terapia específica para seu tratamento e o alto número de oocistos excretados por indivíduos infectados, em torno de $10^{9}$ a $10^{10}$ oocistos, assim como a ampla variedade de hospedeiros que atuam como reservatório da infecção, favorecem a transmissão cruzada ou aumentam o potencial de disseminação da criptosporidiose. ${ }^{7}$ A excreção dos oocistos pode ou não coincidir com o período sintomático da doença, podendo haver imprecisões quanto a sua real ocorrência, pela carência de mais informações da incidência em indivíduos assintomáticos. ${ }^{2}$

A população de idosos apresenta maior susceptibilidade à criptosporidiose. ${ }^{8-10} \mathrm{O}$ número de casos fatais por patógenos entéricos específicos apresenta-se de 10 a 100 vezes maior em idosos que na população em geral. ${ }^{11-13}$

Estudos destacam o papel dos animais de estimação, em especial cães e gatos, aportando significantes benefícios para as pessoas e para a sociedade, contribuindo para o desenvolvimento físico, social e emocional das crianças e com o bem-estar de seus proprietários, em particular de idosos. ${ }^{14}$ No entanto, animais de companhia podem constituir importante fonte de infecção 
para o homem, determinando doenças genericamente denominadas zoonoses, como a criptosporidiose. ${ }^{14,15}$ Caso agravante quanto a essa infecção se dá pelo fato de que grande parte dos animais infectados são portadores assintomáticos. ${ }^{14}$

Estudos reportam prevalência de criptosporidiose e giardíase em populações de felinos variável, geralmente alta, porém a maioria apresenta valores em torno de $12 \%{ }^{16}$ A variabilidade é parte devida à diversidade de técnicas usadas para sua detecção, sendo a técnica mais sensível a reação em cadeia de polimerase (PCR). ${ }^{17,18}$

Neste quadro ainda pouco explorado se insere este artigo, que objetiva evidenciar a prevalência e os riscos relativos da criptosporidiose em animais domésticos de companhia pertencentes a uma amostra da população de idosos do município de Teresópolis, Estado do Rio de Janeiro.

\section{MATERIAL E MÉTODOS}

Local de Estudo

O local de estudo do objeto deste artigo foi o município de Teresópolis. Suas coordenadas compreendem os valores de $22^{\circ} 24^{\prime} 43^{\prime \prime}$ de latitude e $42^{\circ} 57^{\prime}$ 57' de longitude. De acordo com o Censo Demográfico do IBGE, ${ }^{19}$ apresenta um total de 138.081 habitantes com 115.198 $(83,5 \%)$ habitantes na zona urbana e 22.883 $(16,5 \%)$ habitantes na zona rural, com densidade demográfica de 158,7 hab/ $\mathrm{km}^{2}$ e taxa de urbanização de 83,9\%.

\section{População de Estudo}

A pesquisa foi desenvolvida por meio de estudo transversal envolvendo as populações de idosos e gatos de companhia. Foram elegíveis para estudo idosos (acima de 60 anos de idade) de ambos os sexos, residentes no município de Teresópolis, que tinham em domicílio gatos e que compareceram a um posto de vacinação do município no período das campanhas nacionais de vacinação contra gripe de 2009 e 2010, respectivamente. Foram identificados 102 idosos nessas duas campanhas, os quais concordaram com o termo de consentimento para o estudo, preenchendo questionário com dados de anamnese, dados de localização da residência e condições de manejo do animal no domicílio. Considerou-se apenas um felino por proprietário idoso independentemente de haver mais animais de companhia no domicílio.

Dentro das residências, foram verificadas condições de manejo e sanidade do animal, com dados gerais de anamnese envolvendo o estado geral do animal, suas mucosas, temperatura retal, apresentação das fezes, histórico de diarreia, alimentação por ração ou não, procedência da água ingerida e local de permanência do animal (interno ou externo).

\section{Amostragem}

Para a coleta das amostras de fezes, foram utilizados frascos descartáveis (coletor universal) contendo solução conservadora de MIF (merbromino, iodo e formol). Os recipientes foram entregues aos responsáveis após identificação prévia com o número do domicílio, nome do morador e a identificação do animal amostrado naquela residência. $\mathrm{Na}$ primeira visita, foram dadas as instruções de como coletar a amostra fecal e foi marcada a data de retorno para recolhimento da mesma.

Para o instrumento aplicado, os participantes davam informações referentes ao sexo, a idade do proprietário agrupados por faixa etária (60 a 64 anos, 65 a 69 anos, 70 a 74 anos e acima de 75 anos), hábito de tabagismo, estado civil (solteiro, união qualquer ou viúvo) e a presença de diarreia. Quanto aos felinos, os participantes respondiam sobre variáveis como sexo, idade do animal (não definida, 0 a 2,0 anos, 2,1 a 4,0 anos, 4,1 a 6,0 anos e acima de 6,1 anos), estimativa de peso (não definido, 1,0 a 2,5kg, 2,6 a 4,0kg, 4,1 a 5,5kg e 5,6 a 7,0kg), tipo de água ingerida (outra fonte, filtrada ou clorada), permanência no interior, exterior da casa ou ambos e presença de diarreia. 


\section{Exames Parasitológicos}

Foram recolhidas amostras fecais das pessoas participantes e de seus felinos e posteriormente processadas no laboratório de Parasitologia da Universidade Federal Fluminense e no Laboratório de Imunologia e Imunogenética em Doenças Infecciosas do Instituto de Pesquisas Evandro Chagas.

Todas as amostras conservadas em MIF foram submetidas à identificação de oocistos de Cryptosporidium, por meio de esfregaços corados pela técnica de Ziehl-Neelseen modificada. ${ }^{20}$ De igual forma, todas as amostras congeladas foram avaliadas pelo teste de imunofluorescêmcia para identificação por meio de anticorpos monoclonais e policlonais contra o antígeno de superfície do Cryptosporidium spp. E, quando positivas, foram confirmadas pela extração do DNA e identificação por PCR. ${ }^{21}$

\section{Análise Estatística}

A prevalência da infecção por Cryptosporidium spp. nos felinos foi calculada para os fatores de risco sexo, idade, peso, tipo de ingestão de água (filtrada, clorada ou outra fonte), ocorrência de diarreia e frequência de domicilio (interior ou exterior da casa). Para os proprietários dos felinos, utilizaram-se os seguintes fatores de risco: sexo, idade, fumo (presença ou ausência do hábito), ocorrência de diarreia e estado civil. Para os felinos e seus respectivos donos, foram obtidas por meio de variáveis categorizadas, o caso de Cryptosporidium spp., por meio de Ziehl-Neelseen (presença ou ausência), o número de occistos por campo (nenhum, 1, 2, 3, acima de 4), e caso de Cryptosporidium spp., por meio de Elisa (presença ou ausência). Foi obtida a razão de prevalência de diarreia em proprietários idosos e seus respectivos felinos segundo a positividade para Cryptosporidium spp., pelos métodos Ziehl-Neelseen modificado, número de oocistos por campo e Elisa.

Uma análise univariada foi realizada objetivando verificar o efeito de cada possível fator de risco usando distribuição de frequência do fator em relação a positividade por Cryptosporidium spp. A seguir, foi realizada regressão logística incondicional para testar os efeitos das variáveis independentes sobre a variável caso de Cryptosporidium spp. por meio de Ziehl-Neelseen (presença ou ausência) como variável dependente. Valores da associação entre as variáveis por meio de $\mathrm{X}^{2}$ foram obtidos. A razão de chance estimada (OR) e seus intervalos de confiança (95\% IC) foram obtidos como medidas do efeito preditor.

\section{Ética}

Registre-se que o Comitê de Ética em Pesquisas da Ensp/Fiocruz aprovou o presente estudo (registro $\mathrm{n}^{\circ}$ 43/2008), estando os procedimentos de acordo com a Resolução $\mathrm{n}^{\circ}$ 196/96 do Conselho Nacional de Saúde.

\section{RESULTADOS}

A média de idade dos 102 idosos proprietários de felinos de companhia participantes deste estudo foi de $66,7 \pm 4,58$, mediana de 66 anos, sendo a idade mínima de 60 anos e a máxima de 82 anos. O grupo etário de 65 a 69 anos e mais concentrou $43,1 \%$ dos participantes e observou-se predomínio de idosos do sexo feminino $(75,5 \%)$. Observou-se $82,4 \%$ dos idosos livres do hábito de tabagismo e predomínio estado civil de $84,3 \%$ para união de qualquer tipo. Os felinos fêmeas $(59,8 \%)$ predominaram sobre os machos $(40,2 \%)$, sendo a maioria sem idade estimada $(65,7 \%)$ e peso estimado de 2,6 a 4,0kg $(67,6 \%)$ na maior parte. O total de $79,4 \%$ dos felinos transita tanto na parte interna quanto externa do domicílio e a maioria $(56,9 \%)$ ingere água de outras fontes que não seja água filtrada ou clorada.

A prevalência de diarreia nos proprietários idosos foi de $29,4 \%$, ao passo que nos felinos foi de $24,5 \%$. Foi identificada presença de um ou mais oocistos de Cryptosporidium spp. pela coloração de Ziehl-Neelseen modificada em 16,7\% dos idosos proprietários e 12,7\% dos felinos de companhia. Ambos, idosos (8,8\%) e felinos (6,9\%), apresentaram apenas um oocisto por campo. 
Quanto ao método imunoenzimático, 8,8\% dos idosos e $3,9 \%$ dos felinos expressaram positividade para a presença do Cryptosporidium, sendo todos os positivos confirmados pela PCR (Tabela 1).

Tabela 1 - Distribuição de proprietários idosos e felinos em dados de diarreia, presença de oocistos nos exames laboratoriais e número de oocistos por campo. Teresópolis-RJ, 2010.

\begin{tabular}{lcc}
\hline & Variáveis & \\
\hline Diarreia & Número & $\%$ \\
\hline Proprietários idosos & 72 & 70,6 \\
$\quad$ Negativo & 30 & 29,4 \\
Positivo & & \\
Felinos & 77 & 75,5 \\
$\quad$ Negativo & 25 & 24,5 \\
$\quad$ Positivo & Número & $\%$ \\
\hline Positividade para Cryptosporidium spp. em ZNM* & & \\
\hline Proprietários idosos & 85 & 83,3 \\
$\quad$ Negativo & 17 & 16,7 \\
Positivo & & \\
Felinos & 89 & 87,3 \\
$\quad$ Negativo & 13 & 12,7 \\
$\quad$ Positivo & Número & $\%$ \\
\hline Número de oocistos de Cryptosporidium spp. por campo & & \\
\hline
\end{tabular}

Proprietários idosos

$\begin{array}{lll}1 & 9 & 8,8 \\ 2 & 4 & 3,9 \\ 3 & 3 & 2,9 \\ 4 \text { ou mais } & 1 & 1,0\end{array}$

Felinos

\begin{tabular}{lcc}
1 & 7 & 6.9 \\
2 & 4 & 3,9 \\
3 & 1 & 1,0 \\
4 ou mais & 1 & 1,0 \\
\hline Positividade para Cryptosporidium spp. em TI/PCR ** & Número & $\%$ \\
\hline Proprietários idosos & & \\
Negativo & 93 & 91,2 \\
Positivo & 9 & 8,8 \\
Felinos & & \\
Negativo & 98 & 96,1 \\
Positivo & 4 & 3,9 \\
\hline
\end{tabular}

*ZNM $=$ Ziehl-Neelsen modificada

**TI/PCR = Teste Imunoenzimático confirmado pela reação em cadeia de polimerase (PCR) 
A análise da razão de prevalência de diarreia segundo a presença de oocistos pelo método de coloração Ziehl-Neelseen modificada evidenciou forte associação em idosos (RP = 4,37, IC a 95\%: 2,67 - 7,16), porém com menor força de associação, mas ainda com significância estatística para felinos (RP = 2,16, IC a 95\%: 1,06 - 4,39). Já por PCR houve semelhante força de associação em idosos (RP = 4,43, IC a 95\%: 3,04 - 6,45), porém observou-se aumento na força de associação para felinos (RP = 4,67, IC a 95\%: 3,9 - 6,81).
Esses resultados, quando estratificados por número de oocistos por campo, demonstraram efeito dose resposta para idosos com aumento das medidas de efeito, estabilizando-se para dois ou mais oocistos numa RP de 5,31 (IC 95\%: 1,08 - 9,54). Diferente comportamento observouse na dose resposta para felinos com aumento das medidas de efeito à medida que aumenta o número de oocistos por campo, embora seus respectivos IC a 95\% não sejam estatisticamente significativos (Tabela 2).

Tabela 2 - Razão de prevalência de diarreia em proprietários idosos e felinos segundo a positividade para Cryptosporidium spp. pelos métodos Ziehl-Neelseen modificado, número de oocistos por campo e PCR. Teresópolis-RJ, 2010.

\begin{tabular}{|c|c|c|c|c|c|}
\hline \multicolumn{6}{|c|}{ Razão de Prevalência } \\
\hline Variáveis & & Diarreia & & & \\
\hline $\begin{array}{c}\text { Presença de oocistos } \\
\text { por ZNM* }\end{array}$ & Positivo (\%) & $\begin{array}{l}\text { Negativo } \\
(\%)\end{array}$ & $\begin{array}{l}\text { Total } \\
\mathrm{N}^{\circ}(\%)\end{array}$ & $\mathrm{RP}$ & IC $(95 \%)$ \\
\hline \multicolumn{6}{|l|}{ Proprietários Idosos } \\
\hline positivo & $14(82,35)$ & $3(17,35)$ & $17(16,67)$ & & \\
\hline negativo & $16(18,82)$ & $69(81,18)$ & $85(83,33)$ & 4,37 & $2.67-7,16$ \\
\hline \multicolumn{6}{|l|}{ Felinos } \\
\hline positivo & $6(46,15)$ & $7(53,85)$ & $13(12,75)$ & & \\
\hline negativo & $19(21,35)$ & $70(78,65)$ & $89(87,25)$ & 2,16 & $1,06-4,39$ \\
\hline $\begin{array}{l}\text { Número de oocistos por } \\
\text { campo }\end{array}$ & Positivo (\%) & $\begin{array}{l}\text { Negativo } \\
(\%)\end{array}$ & $\begin{array}{c}\text { Total } \\
\mathrm{N}^{\circ}(\%)\end{array}$ & $\mathrm{RP}$ & IC $(95 \%)$ \\
\hline \multicolumn{6}{|l|}{ Proprietários Idosos } \\
\hline 1 & $6(66,66)$ & $3(33,34)$ & $9(8,82)$ & 3,54 & $2,15-4,92$ \\
\hline 2 & $4(100,00)$ & $0(0,00)$ & $4(3,92)$ & 5,31 & $1,08-9,54$ \\
\hline 3 & $3(100,00)$ & $0(0,00)$ & $3(2,95)$ & 5,31 & $0,25-10,36$ \\
\hline 4 ou mais & $1(100,00)$ & $0(0,00)$ & $1(0,98)$ & 5,31 & $0,00-14,68$ \\
\hline \multicolumn{6}{|l|}{ Felinos } \\
\hline 1 & $2(28,57)$ & $5(71,43)$ & $7(6,86)$ & 1,34 & $0,63-2,05$ \\
\hline 2 & $2(50,00)$ & $2(50,00)$ & $4(3,92)$ & 2,34 & $0,34-4,34$ \\
\hline 3 & $1(100,00)$ & $0(0,00)$ & $1(0,98)$ & 4,68 & $0,21-9,27$ \\
\hline 4 ou mais & $1(100,00)$ & $0(0,00)$ & $1(0,98)$ & 4,68 & $0,21-9,27$ \\
\hline
\end{tabular}




\begin{tabular}{lccccc}
\hline $\begin{array}{l}\text { Presença de oocistos } \\
\text { por TI / PCR** }\end{array}$ & Positivo (\%) & $\begin{array}{c}\text { Negativo } \\
(\%)\end{array}$ & $\begin{array}{c}\text { Total } \\
\mathrm{N}^{\circ}(\%)\end{array}$ & RP & IC (95\%) \\
\hline $\begin{array}{l}\text { Proprietários Idosos } \\
\text { positivo }\end{array}$ & $9(100,00)$ & $0(00,00)$ & $9(8,82)$ & & \\
$\quad$ negativo & $21(22,58)$ & $72(77,42)$ & $93(91,18)$ & 4,43 & $3,04-6,45$ \\
$\begin{array}{l}\text { Felinos } \\
\text { positivo }\end{array}$ & $4(100,00)$ & $0(00,00)$ & $4(3,92)$ & & \\
$\quad$ negativo & $21(21,43)$ & $77(78,57)$ & $98(96,08)$ & 4,67 & $3,19-6,81$ \\
\hline
\end{tabular}

*ZNM $=$ Ziehl-Neelsen modificada

**TI/PCR $=$ Teste Imunoenzimático confirmado pela reação em cadeia de polimerase (PCR)

RP = Razão de Prevalência

$\mathrm{IC}=$ Intervalo de Confiança

Não foram observadas relações entre a presença de Cryptosporidium spp. e as variáveis obtidas como possíveis fatores de risco, mas alguns resultados podem ser destacados. Em relação aos animais, percebeu-se reduzido aumento da chance de infecção por Cryptosporidium spp. para as fêmeas em relação aos machos $(\mathrm{OR}=1.08, \mathrm{IC}=0.32-3.59)$. Observou-se aumento da chance de infecção do felino com o aumento da idade (OR=1.22, 1.902.85), apesar de não estatisticamente significativa.
Em relação ao tipo de água ingerida pelo animal, observa-se um efeito protetor com a redução da chance de infecção à medida que o animal bebe água filtrada $(\mathrm{OR}=0.80, \mathrm{IC}=0.22-2.90)$ e clorada $(\mathrm{OR}=0.78, \mathrm{IC}=0.08-7.11)$. A diarreia mostrou-se como um fator resultado da infecção por Cryptosporidium spp. $(\mathrm{OR}=3.15, \mathrm{IC}=0.94$ 10.51), sendo que o não encontro de significância neste caso pode ser puramente um resultado do tamanho amostral (Tabela 3). 
Tabela 3 - Análise de regressão logística para determinar os fatores associados da infecção por Cryptosporidium spp. em felinos do município de Teresópolis-RJ. 2010.

\begin{tabular}{|c|c|c|c|c|c|c|c|c|}
\hline Variável & Categoria & Testado & $\begin{array}{l}\text { Positivo } \\
\mathrm{N}\end{array}$ & $\begin{array}{c}(\mathrm{N}=9) \\
\%\end{array}$ & $\begin{array}{c}X^{2} \\
\text { P valor }\end{array}$ & OR & $95 \%$ I.C. & $\mathrm{P}$ \\
\hline \multirow{2}{*}{ Sexo } & Macho & 41 & 5 & 12,2 & 0,89 & 1 & & \\
\hline & Fêmea & 61 & 8 & 13,1 & & 1,08 & $0,32-3,59$ & 0,89 \\
\hline \multirow{4}{*}{ Idade (anos) } & indefinida & 67 & 7 & 10,4 & 0,81 & 1 & & \\
\hline & 0 a 2,0 & 8 & 1 & 12,5 & & 1,22 & $0,13-11,46$ & 0,85 \\
\hline & 2,1 a 4,0 & 22 & 4 & 18,2 & & 1,90 & $0,50-7,25$ & 0,34 \\
\hline & $>4,1$ & 5 & 1 & 25,0 & & 2,85 & $0,26-31,32$ & 0,39 \\
\hline \multirow{3}{*}{$\begin{array}{l}\text { Estimativa } \\
\text { de peso }\end{array}$} & 1,0 a 2,5 & 22 & 4 & 18,2 & 0,67 & 1 & & \\
\hline & 2,6 a 4,0 & 69 & 9 & 13,0 & 0 & 0,67 & $0,18-2,45$ & 0,55 \\
\hline & $>4,1$ & 11 & 0 & 0 & & - & - & - \\
\hline \multirow{3}{*}{$\begin{array}{l}\text { Tipo de } \\
\text { ingestão de } \\
\text { água }\end{array}$} & Outra & 58 & 8 & 13,8 & 0,78 & 1 & & \\
\hline & Filtrada & 35 & 4 & 11,4 & & 0,80 & $0,22-2,90$ & 0,74 \\
\hline & Clorada & 9 & 1 & 11,1 & & 0,78 & $0,08-7,11$ & 0,82 \\
\hline \multirow{3}{*}{$\begin{array}{c}\text { Frequência } \\
\text { no domicílio }\end{array}$} & Ambos & 81 & 12 & 14,8 & 0,24 & 1 & & \\
\hline & Interior & 8 & 0 & 0 & & - & & \\
\hline & Exterior & 13 & 1 & 7,7 & & 0,47 & $0,057-4,03$ & 0,49 \\
\hline \multirow{2}{*}{ Diarreia } & Não & 77 & 7 & 9,09 & 0,06 & 1 & & \\
\hline & Sim & 25 & 6 & 24 & & 3,15 & $0,94-10,51$ & 0,06 \\
\hline
\end{tabular}

Para os fatores de risco associados à infecção por Cryptosporidium spp. nos proprietários dos animais, a regressão logística não apresentou associações significativas ao nível de $\mathrm{p}<0.05$, com exceção da variável diarreia. Da mesma forma, alguns resultados podem ser destacados. Observou-se maior chance de infecção para as mulheres em relação aos homens $(\mathrm{OR}=2,78$, $\mathrm{IC}=0.59-12$ ), e um aparente efeito protetor pela infecção com o aumento da idade das pessoas $(\mathrm{OR}=0.37, \quad \mathrm{IC}=0.05-4,33)$. A ocorrência de diarreia apresentou forte associação com a infecção por Cryptosporidium spp. (OR=20.12, IC $=5.16-78.44)$ (Tabela 4). 
Tabela 4 - Análise de regressão logística para determinar os fatores associados da infecção por Cryptosporidium spp. em moradores do município de Teresópolis-RJ. 2010.

\begin{tabular}{|c|c|c|c|c|c|c|c|c|}
\hline Variável & Categoria & Testado & $\begin{array}{c}\text { Positivo } \\
\text { N }\end{array}$ & $\begin{array}{c}(\mathrm{N}=9) \\
\%\end{array}$ & $\begin{array}{c}\mathrm{X}^{2} \\
\text { P valor }\end{array}$ & OR & $95 \%$ I.C. & $\mathrm{P}$ \\
\hline \multirow{2}{*}{ Sexo } & Masculino & 25 & 2 & 8,0 & 0,15 & 1 & & \\
\hline & Feminino & 77 & 15 & 19,5 & & 2,78 & $0,59-13,12$ & 0,19 \\
\hline \multirow{3}{*}{ Idade (anos) } & 60 a 64 & 31 & 8 & 25,0 & 0,28 & 1 & & \\
\hline & 65 a 69 & 44 & 5 & 11,1 & & 0,37 & $0,11-1,27$ & 0,11 \\
\hline & $>70$ & 24 & 4 & 16,0 & & 0,57 & $0,15-2,17$ & 0,41 \\
\hline \multirow{2}{*}{ Fumo } & Não & 84 & 15 & 17,9 & 0,46 & 1 & & \\
\hline & $\operatorname{Sim}$ & 18 & 2 & 11,1 & & 0,57 & $0,11-2,77$ & 0,49 \\
\hline \multirow{3}{*}{ Est. civil } & Solteiro & 6 & 1 & 16,7 & 0,95 & 1 & & \\
\hline & União qualquer & 86 & 14 & 16,3 & & 0,97 & $0,10-8,97$ & 0,98 \\
\hline & viúvo & 10 & 2 & 20,0 & & 1,25 & $0,08-17,65$ & 0,86 \\
\hline \multirow{2}{*}{ Diarreia } & Não & 72 & 3 & 4,2 & 0,001 & 1 & & \\
\hline & Sim & 30 & 14 & 46,7 & & 20,12 & $5,16-78,44$ & $<0,001$ \\
\hline
\end{tabular}

\section{DISCUSSÃO}

Os 102 indivíduos idosos residentes em Teresópolis-RJ que compuseram a amostra da população estudada e que demandaram a campanha de vacinação contra a gripe nos anos de 2009 e 2010 eram predominantemente do sexo feminino, proprietários de pelo menos um felino doméstico e, na sua maioria, permitiam que os animais domiciliados transitassem dentro e fora das residências.

A elevada prevalência de Cryptosporidium em animais na região de Teresópolis é compatível com os achados de Pereira e colaboradores, ${ }^{22}$ quando detectaram elevada contaminação (100\%) deste protozoário nas verduras consumidas pela população, sinalizando dados preocupantes quanto ao tratamento de água e de esgoto.

O estudo da população de gatos (102) através da identificação de oocistos pela presença de Cryptosporidium spp. evidenciou prevalência de $12,7 \%$, compatível com a variação global de resultados em diferentes países como 3,8\% no Japão, ${ }^{23} 12,3 \%$ na Escócia ${ }^{16}$ e os $24,5 \%$ de 200 felinos de Turin, na Itália. ${ }^{24}$ Semelhante estudo realizado em 51 felinos obteve uma prevalência de 3,9\% no município de Andradina-SP. ${ }^{25}$ 
A população idosa, na maioria das vezes, depende psicologicamente da companhia de animais, inclusive por indicação médica. As doenças infecciosas são causas comuns do aumento de morbidades e mortalidades em pacientes idosos e se revelam como problema frequente na prática diária da Geriatria. ${ }^{12}$ As infecções em idosos são de características diferenciadas das apresentadas na população jovem, sendo essas diferenças atribuídas às alterações imunológicas ou mau funcionamento orgânico. ${ }^{11}$

A positividade para Cryptosporidium nos animais que conviviam com idosos de 70-74 anos e com 75 ou mais $(43,9 \%)$ foi muito elevada, configurando maior probabilidade de exposição desta parasitose em grupos populacionais considerados mais suscetíveis. Estudo realizado no Irã ${ }^{13} \mathrm{com} 400$ indivíduos mostrou que no grupo de pessoas acima de 51 anos, que apresentava história de diarreia, houve prevalência de $25 \%$ de positividade para o Cryptosporidium spp.

Pode-se também observar que a população canina de um animal por domicílio, comparada aos casos de superpopulação (mais que 5 animais), apresentou menor prevalência de diarreia, provavelmente como resultado do contato com outros animas (via oral/fecal), evitando uma contaminação cruzada. Observou-se também que os animais que eram domiciliados dentro das residências apresentaram um razão de prevalência protetora, com redução da probabilidade de apresentar diarreia, talvez pelo fato de o ambiente interno estar em condições de menor exposição a infecção por Cryptosporidium spp.

Os animais domésticos são fontes de infecção assintomáticos de protozoários do gênero Cryptosporidium, albergando-os em seu trato intestinal e veiculando oocistos viáveis ao ambiente através de suas fezes. ${ }^{2,3} \mathrm{O}$ preocupante é que a alta prevalência de criptosporidiose só se manifesta clinicamente com quadro diarreico nos casos de debilidade do animal. ${ }^{6}$ A prevalência de oocistos de Cryptosporidium spp. aumenta na medida em que aumenta a densidade populacional de animais de companhia por residência. Tal fato sinaliza a necessidade de maior aprofundamento desta investigação, uma vez que existem poucos estudos que exploram a relação de criptosporidiose na população humana com animais de companhia. Devido a isso, deve-se melhorar a avaliação do nível que tal relação se conforma, ou seja, idosos/ animais de companhia, pelo potencial ciclo de exposição aos idosos, justificando dessa maneira a tentativa de se conhecer o que está ocorrendo neste grupo específico da população, aqui preliminarmente estudada.

A utilização de animais como terapia vem sendo utilizada desde o século XVIII, focada ao tratamento de doentes mentais. ${ }^{14}$ Pesquisas subsequentes voltaram-se aquelas sobre que efeitos a interação homem/animal incidiria favoravelmente sobre parâmetros fisiológicos e saúde cardiovascular humana. ' Observouse que tal interação poderia promover a saúde física através de três mecanismos básicos que incluem a diminuição da solidão e da depressão; diminuindo a ansiedade, os efeitos do sistema nervoso simpático e aumentando o estímulo para prática de exercícios. Consequentemente, há um impacto positivo no dia a dia, repercutindo numa melhoria na qualidade de vida e na saúde física dos indivíduos. ${ }^{8,11}$

\section{CONCLUSÕES}

Inicia-se o século XXI amargando sérios desafios sociais, com reflexos diretos sobre a saúde pública. O aumento da expectativa de vida, com o consequente aumento da população idosa, e a necessária atenção a esse crescente grupo, constitui-se um grande desafio social. A atenção à saúde neste grupo específico é ainda incipiente, e evidentemente vários fatores contribuirão para o aumento da incidência de doenças parasitárias, nas quais a criptosporidiose sinaliza uma expansão preocupante, pelas características do parasito e pela proximidade da exposição pelos animais de companhia.

Assim, os achados obtidos com esta pesquisa podem ser considerados pertinentes, por demonstrarem a relação zoonótica do Cryptosporidium spp. presente nas amostras fecais dos animais de companhia do grupo populacional de idosos estudados. 


\section{REFERÊNCIAS}

1. O'donoghue PJ. Cryptosporidium and cryptosporidiosis in man and animals. Int J Parasitol 1995; 25(2): 139-95.

2. Teunis PFM, Havelaar AH. Risk assessment for protozoan parasites. Internat Biodegr Biodet 2002; 9:122-46.

3. Tzipori S. Cryptosporidiosis in animals and humans. Microbiol. Rev. 1983; 47: 84-6.

4. Fayer R, Ungar BLP. Cryptosporidium spp. and cryptosporidiosis. Microbiological Reviews 1986; 458-83.

5. Heller L, et al. Oocistos de Cryptosporidium e cistos de Giardia: circulação no ambiente e riscos à saúde humana. Epid Serv Saúde 2004; 13(2):79 - 92.

6. Acha PN, Szyfres B. Zoonosis y enfermidades transmisibles comunes al hombre y a los animales. 2 ed. Washington: Organización Panamericana de la Salud; 1989 .

7. Figueiredo HCP, et al. Excreção de oocistos de Cryptosporidium parvum em cães saudáveis das cidades de Lavras e Viçosa, Estado de Minas Gerais, Brasil. Cien Rural 2004; 34(5):1625-27.

8. Neill MA, et al. Cryptosporidiosis: an unrecognized cause of diarrhea in elderly hospitalized patients. Clin Infect Dis 1996; 22(1):168-70.

9. Werner $\mathrm{H}$, Kuntsche J. Infection in the elderly-what is different? Zeit für Geront Geriat 2000; 33(5):350-56.

10. Gambhir S, Jaiswal JP, Nath G. Significance of Cryptosporidium as an aetiology of acute infectious diarrhoea in elderly Indians. Trop Med Int Health 2003; 8(5):415-19.

11. Meyers BR. Infectious diseases in the elderly: an overview. Geriatrics 1989; 44:4-6.

12. Chantri T, Kavita P. Diarrheal diseases in the elderly. Clin Geriatr Med 2007; 23(4): 833-56.

13. Mirzaei M. Prevalence of Cryptosporidium spp. infection in diarrheic and non-diarrheic humans in Iran. Kor J Parasitol 2007; 45(2): 133-37.

14. Robertson ID, et al. The role of companion animals in the emergence of parasitic zoonosis. Int J Parasitol 2000; 30:1369-77.
15. Lallo MA, Bondan EF. Prevalência de Cryptosporidium spp. em cães de instituições da cidade de São Paulo, Brasil. Rev S Publ 2006; 40(1):120-25.

16. Nash AS, Mtambo MM, Gibbs HA. Cryptosporidium infection in farm cats in the Glasgow area. Veterinary Record 1993; 133-577.

17. McGlade TR, et al. High prevalence of Giardia detected in cats by PCR. Veterinary Parasitology 2003; 197-205.

18. Gonçalves EMN, et al. Protocol for DNA extraction of Cryptosporidium spp. oocystes in fecal samples. Rev Inst Med Trop S Paulo 2008; 50(3): 165-7.

19. IBGE. Instituto Brasileiro de Geografia e Estatística. Projeto Teresópolis. Hydrology and elevation Teresópolis (Map). Scale Layer: 1:50.000. 4d ed., DAMTD, 2000. [Acesso 12 abr 2011]. Disponível em: http://www.ibge.gov.br/

20. De Carli GA, Saraiva PJ. Diagnóstico de Laboratório da Criptosporidiose Humana. Rev. Bras. Anal. Clín. 1991; 23(2) 26-30.

21. Higgins JA, et al. Rapid extraction of DNA from Escherichia coli and Cryptosporidium parvum for use in PCR. Applied and Environmental Microbiology 2001; 64(11) 5321-4.

22. Pereira CRA, Ferreira AP, Koifman RJ. Detecção de Cryptosporidium parvum em alfaces frescas para consumo cru. Estudo de caso: Teresópolis, Rio de Janeiro, Brasil. Gaia Scentia 2008; 2(2):31-6.

23. Mtambo MM, et al. Cryptosporidium infection in the cats: prevalence of infection in domestic and feral cats in the Glasgow area. Vet Rec 1991; (129) 502-4.

24. Rambozzi L, et al. Prevalence of Cryptosporidium infection in cats in Turin and analysis of risk factors. J of Feline MedSurg 2007; (9)392-6.

24. Coelho WMD, et al. Ocorrência de parasitos gastrintestinais em amostras fecais de felinos no município de Andradina, São Paulo. Rev. Bras. Parasitol. Vet. Jaboticabal, 2009; 18(2) 46-9. 